\title{
Case Report \\ Lack of Catch-Up Growth with Growth Hormone Treatment in a Child Born Small for Gestational Age Leading to a Diagnosis of Noonan Syndrome with a Pathogenic PTPN11 Variant
}

\author{
Daniel J. Olivieri, ${ }^{1}$ Lauren J. Massingham, ${ }^{2}$ Jennifer L. Schwab, ${ }^{2}$ \\ and Jose Bernardo Quintos $\mathbb{D}^{3}$ \\ ${ }^{1}$ The Warren Alpert Medical School of Brown University, Providence, RI, USA \\ ${ }^{2}$ Division of Genetics, Hasbro Children's Hospital/Warren Alpert Medical School of Brown University, 593 Eddy Street, \\ Providence, RI 02903, USA \\ ${ }^{3}$ Division of Pediatric Endocrinology and Diabetes, Hasbro Children's Hospital/Warren Alpert Medical School of \\ Brown University, 593 Eddy Street, Providence, RI 02903, USA \\ Correspondence should be addressed to Jose Bernardo Quintos; jbquintos@brown.edu
}

Received 25 February 2021; Accepted 27 May 2021; Published 7 June 2021

Academic Editor: J. Paul Frindik

Copyright ( 2021 Daniel J. Olivieri et al. This is an open access article distributed under the Creative Commons Attribution License, which permits unrestricted use, distribution, and reproduction in any medium, provided the original work is properly cited.

\begin{abstract}
Background. Growth hormone (GH) treatment increases the adult height of short children born small for gestational age (SGA). Catch-up growth is associated with a younger age, shorter height, and prepubertal status at the onset of GH treatment. We report a 12 11/12-year-old girl born SGA who received GH for 5 years without catch-up growth and was diagnosed with Noonan Syndrome (NS). Results. A 5-year-and-9-month-old 46, XX girl born SGA was started on GH treatment at a dose of $0.32 \mathrm{mg} / \mathrm{kg} /$ week. Her midparental target height is $158.6 \mathrm{~cm}$. Endocrine work up showed an IGF-1 level $69 \mathrm{ng} / \mathrm{ml}$ (Normal (N): 55-238 ng/ml), IGFBP3 $2.6 \mathrm{mg} / \mathrm{L}(\mathrm{N}: 1.9-5.2 \mathrm{mg} / \mathrm{L})$, TSH $3.2 \mathrm{mIU} / \mathrm{L}$ (N: 0.35-5.5 mIU/L), and a normal skeletal survey. Height was $96 \mathrm{~cm}(0.1 \%$; Ht SDS -2.9), weight $14 \mathrm{kgs}(1 \%$; Wt SDS -2.3), and Tanner 1 breast and pubic hair were observed. Due to the poor catch-up growth on GH treatment, she was referred to Genetics to elucidate genetic or syndromic causes of short stature. She was noted to have posteriorly rotated ears and slight down slanting of the palpebral fissures. Genetic findings showed a heterozygous pathogenic variant in PTPN11 (c.922A > G (p.Asn308Asp)) diagnostic for NS. This finding is de novo given negative parental testing. She was noted to have a heterozygous missense variant of unknown significance (VUS) in FGFR3: c.746C > A (p.Ser249Tyr). FGFR3 is associated with multiple skeletal dysplasias including thanatophoric dysplasia, achondroplasia, and Crouzon syndrome and hypochondroplasia. Clinical correlation is poor for these syndromes. Conclusion. Diminished catch-up growth and response to GH treatment in a child born SGA led to the diagnosis of NS. The concomitant diagnosis of SGA and NS may have affected the responsiveness of this child to the growth promoting effect of GH treatment.
\end{abstract}

\section{Introduction}

Small for gestational age (SGA) has a global incidence of $3-10 \%$ and results in a higher risk for metabolic dysregulation and reduced fetal growth $[1,2]$. While over $85 \%$ of infants will "catch-up" to their peers by two years of age, nearly $10 \%$ of SGA infants will continue to fall below the 3rd percentile of height until adulthood [3]. Failure to "catchup" to peers-children two standard deviations below the mean for age and sex at two years of age per Food and Drug Administration criteria or four years of age per European Medicines Agency criteria-can warrant Growth Hormone (GH) pharmacologic treatment $[4,5]$. Nonresponders to GH treatment warrant complete metabolic and genetic workup to determine the etiology [6-9]. We present a patient born SGA who was refractory to GH treatment and later found to have an FGFR3 variant of unknown significance (VUS) and a PTPN11 pathogenic variant of Noonan Syndrome (NS). 
Initial clinical presentation, serial measurements, workup, and case management are discussed.

\section{Case Presentation}

The patient initially presented to the pediatric endocrinologist at Hasbro Children's Hospital (Providence, RI, USA) as a five years and two months old female for growth evaluation.

She was born to a 32 -year-old G1P0 $\longrightarrow 2$ mother at 37 weeks, 2 days gestation, via cesarean section and her twin brother (discordant) during an uncomplicated pregnancy. Her birth was notable for intrauterine growth restriction (IUGR) with weight and length more than two standard deviations below the mean $(1.75 \mathrm{~kg}$ and $38.1 \mathrm{~cm}$ length). The perinatal course included a 1-week hospital stay for catch-up growth but no NICU stay. Her twin brother was born at 5 pounds, 1 ounce, and 18 inches length. Maternal medications included levothyroxine, and the mother's past medical history was notable for papillary thyroid cancer. No drugs, alcohol, or cigarettes were reported nor documented in pregnancy. She required early intervention at 6 months for a motor delay (inability to sit up). Her predicted midparental target height is $157 \mathrm{~cm} \pm 10 \mathrm{~cm}$ (62 inches \pm 4 inches) with a lower limit of $147 \mathrm{~cm}$ (58 inches).

A concern for failure to catch up in growth by age four years led to a referral to the pediatric endocrine clinic at five years and two months of age. Her parents denied polyuria, polydipsia, headache, fatigue, fever, weight loss, cold intolerance, sleep disturbance, abdominal pain, and constipation.

The initial laboratory investigation was normal (Table 1). The physical examination findings included a height of $96.1 \mathrm{~cm}(0.2 \%$; SDS of -2.9$)$, a weight of $14.0 \mathrm{~kg}$ (1\%; SDS of $-2.3)$, and a BMI of $15.1 \mathrm{~kg} / \mathrm{m}^{2}(50.3 \%)$. She had Tanner 1 breast and pubic hair and otherwise unremarkable physical examination. Given the height of 2.9 standard deviations below the mean at age 4 years, GH treatment was warranted [10]. She began recombinant growth hormone at a dose of $0.6 \mathrm{mg}$ administered subcutaneously every night at a starting dose of $0.32 \mathrm{mg} / \mathrm{kg} /$ week.

A six-month follow-up visit was notable for an excellent annualized growth rate of $10.4 \mathrm{~cm} /$ year. $\mathrm{GH}$ dose was increased from $0.6 \mathrm{mg}$ SQ to $0.65 \mathrm{mg}$ SQ every night to maintain a dosage of $0.32 \mathrm{mg} / \mathrm{kg} /$ week. She denied side effects of $\mathrm{GH}$ injections including symptoms of pseudotumor cerebri, such as headaches, blurry vision, or vomiting. The subsequent annual growth velocities and height standard deviations (Ht SDS) are presented in Table 2. Additionally, there was a 9-month treatment lapse from years two, three due to financial cost (i.e., high health insurance deductible), resulting in diminished growth (Figures 1 and 2). GH therapy treatment was reinitiated at an age of 8 years.

Due to the continued diminished growth, she was referred to the Division of Genetics at 10 years and 9 months of age to elucidate genetic or syndromic causes of short stature. She was noted to have posteriorly rotated ears and slightly downward slanting of the palpebral fissures. A comprehensive Short Stature Syndrome Panel Plus (sequencing and
TABLE 1: Initial laboratory values.

\begin{tabular}{|c|c|c|}
\hline Description & Value & Reference range \\
\hline \multicolumn{3}{|l|}{ Genetic } \\
\hline Karyotype & 46, XX & - \\
\hline \multicolumn{3}{|l|}{ Thyroid markers } \\
\hline TSH, high sensitivity & $2.977 \mathrm{uIU} / \mathrm{mL}$ & $\begin{array}{c}0.350-5.5 \mathrm{uIU} / \\
\mathrm{mL}\end{array}$ \\
\hline Thyroglobulin Ab & $<15.0 \mathrm{U} / \mathrm{mL}$ & $0.0-60.0 \mathrm{U} / \mathrm{mL}$ \\
\hline Thyroid peroxidase Abs & $<28.0 \mathrm{IU} / \mathrm{mL}$ & $1.0-60.0 \mathrm{IU} / \mathrm{mL}$ \\
\hline \multicolumn{3}{|l|}{ Endocrine } \\
\hline IGF-1 binding protein 3 & $2.6 \mathrm{mg} / \mathrm{L}$ & $1.1-5.2 \mathrm{mg} / \mathrm{L}$ \\
\hline IGF-1 & $69 \mathrm{ng} / \mathrm{mL}$ & $55-238 \mathrm{ng} / \mathrm{mL}$ \\
\hline \multicolumn{3}{|l|}{ Renal } \\
\hline Ultrasound & Normal findings & - \\
\hline \multicolumn{3}{|l|}{ Inflammatory markers } \\
\hline Celiac disease & Negative & - \\
\hline
\end{tabular}

deletion/duplication) from Blueprint Genetics analyzed 374 genes including IGF-1, IGF-1 receptor, IGF-ALS (insulinlike growth factor-binding protein, acid-labile subunit), GH, $\mathrm{GH}$ receptor, GH releasing hormone receptor, and STAT5b demonstrated a heterozygous pathogenic variant in PTPN11 (c.922A > G (p.Asn308Asp)) diagnostic for NS. This finding is de novo as parental testing for the PTPN11 variant was negative. She was noted to have a heterozygous missense variant of unknown significance (VUS) in FGFR3: c.746C > A (p.Ser249Tyr). FGFR3 is associated with multiple skeletal dysplasias including thanatophoric dysplasia, achondroplasia, Crouzon syndrome, and hypochondroplasia. Clinical correlation is poor as our patient's findings are not as severe as typically described for these syndromes. The patient then received comprehensive screening for NS, including a renal ultrasound, EKG, skeletal survey, ophthalmic evaluation, and thyroid panel.

At the last endocrine visit at 12 years and 11 months of age, the patient's height was $138 \mathrm{~cm}(0.4 \%$; SDS $=-2.6)$ and weight was $32.4 \mathrm{~kg}(2.3 \%$; SDS $=-2.0)$ on $2.2 \mathrm{mg} /$ day subcutaneous $\mathrm{GH}$ treatment injections $(0.5 \mathrm{mg} / \mathrm{kg} /$ week $)$. Additionally, she was noted to have Tanner 3 breast development and Tanner 4 pubic hair. Other notable physical examination findings included frontal bossing and triangular facies. Her most recent annualized growth was $5.2 \mathrm{~cm} /$ year $(69 \%$; SDS $=0.52)$. Her most recent bone age was 11 years-11 years and 6 months, with a predicted adult height of $148.5 \mathrm{~cm}-150 \mathrm{~cm}$ vs. the midparental target height is $157 \mathrm{~cm} \pm 10 \mathrm{~cm}$ (62 inches \pm 4 inches) with a lower limit of $147 \mathrm{~cm}$ (58 inches). The plan is to discontinue GH treatment once the bone age is $14-15$ years and growth rate is $<2.5 \mathrm{~cm} /$ year.

\section{Discussion}

We report a 12 11/12-year-old girl born SGA who received $\mathrm{GH}$ for 5 years without catch-up growth and was diagnosed with NS with a PTPN11 pathogenic variant. The concomitant diagnosis of SGA and NS may have affected the responsiveness of this child to the growth-promoting effect of $\mathrm{GH}$ treatment. 
TABLE 2: Annual growth parameters.

\begin{tabular}{lcc}
\hline Year & Height standard deviations ${ }^{\mathrm{a}}$ below mean for age and sex & Growth rate $(\mathrm{cm} /$ year) \\
\hline 0 & -2.9 & - \\
1 & -2.5 & 7.5 \\
2 & -2.2 & 6.7 \\
3 & -2.2 & 4.5 \\
4 & -2.2 & 5.1 \\
5 & -2.5 & 5.1 \\
\hline
\end{tabular}

${ }^{a}$ Height standard deviations refers to the number of standard deviations below the mean height for age and sex.

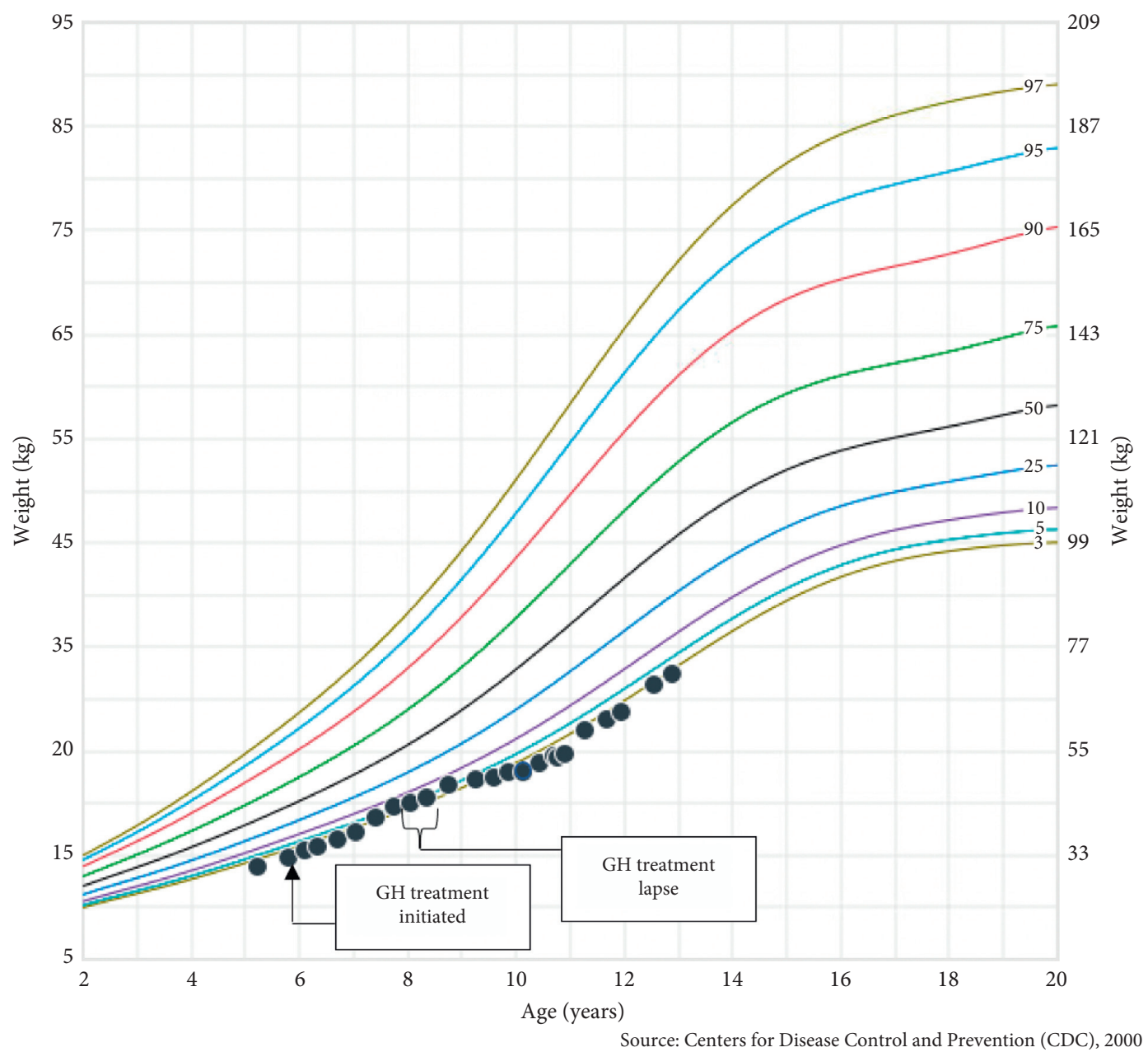

Figure 1: Plotted weight-for-age percentiles for Jane Doe. Centers for Disease Control and Prevention (CDC) weight-for-age percentiles, girls 2 to 20 years old.

Children born SGA require careful follow-up and monitoring to evaluate for developmental and growth-related complications [10]; children born SGA on average weigh less and are shorter than their non-SGA counterparts $[1,11]$. While the majority of SGA infants experience "catchup" growth, nearly $15 \%$ of SGA infants will not "catch-up" by two years of life [12]. Children who remain two or greater standard deviations below the mean for their age and sex warrant consideration for GH treatment [13]. The efficacy of GH treatment in children born SGA has been correlated to earlier treatment initiation, shorter starting height, and decreased starting weight [14]. Important considerations for
GH treatment include financial cost, treatment compliance, and the psychological effects of short stature [15-17]. Despite the strong efficacy of GH treatment associated with children who fit FDA or EMA criteria, some children will remain two standard deviations below their midparental target height refractory to GH therapy [18]. Potential causes of children refractory to $\mathrm{GH}$ include mutations in the $\mathrm{GH}$ receptor, IGF-1 gene, and GH signaling pathway [19]. Specifically, in regard to children born SGA, variability in response to GH treatment has been reported and may be explained through genetic mutations in the GH/GH receptor transduction signaling pathway $[19,20]$. More recent studies 


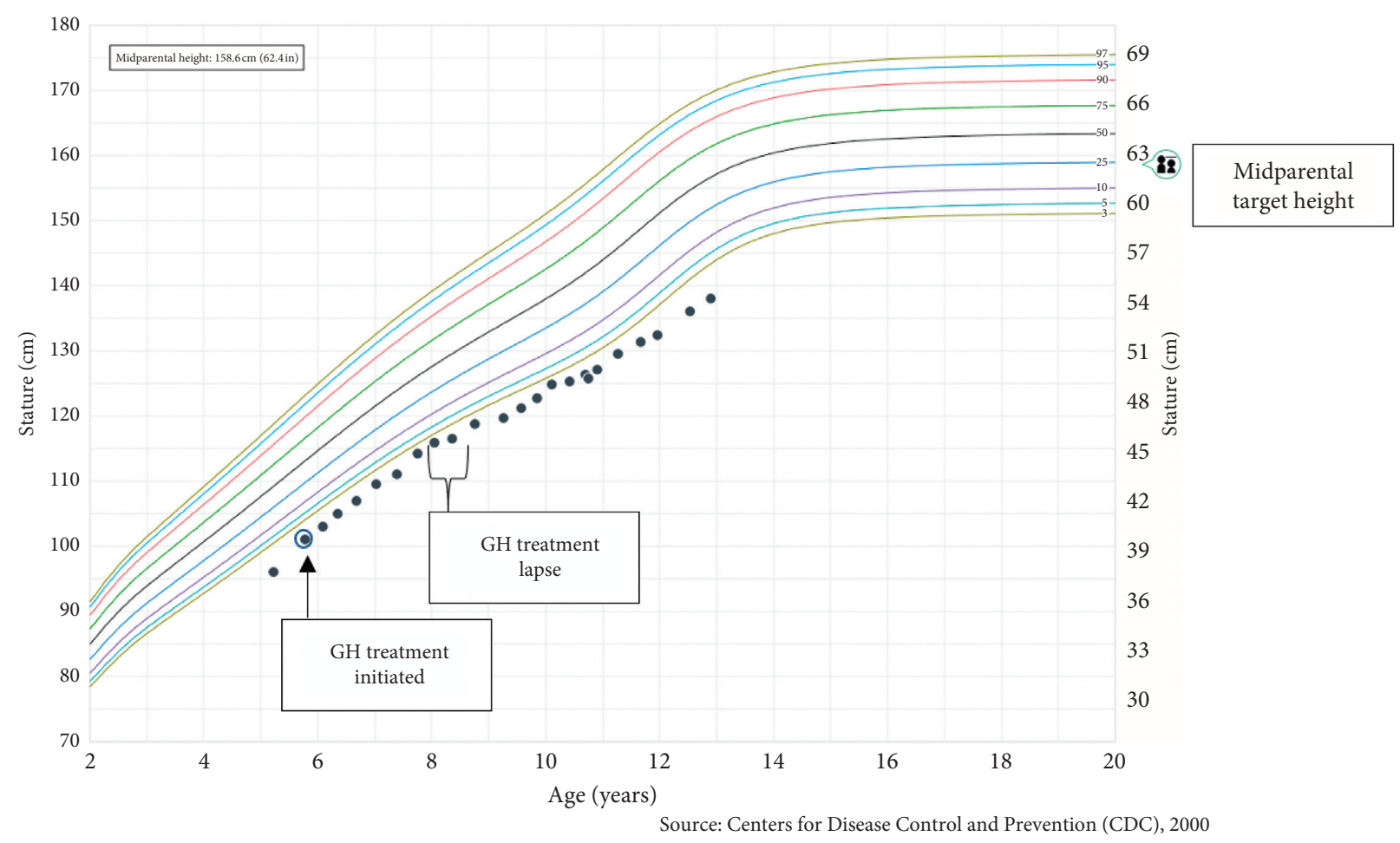

Figure 2: Plotted stature-for-age percentiles for Jane Doe. Centers for Disease Control and Prevention (CDC) stature-for-age percentiles, girls 2 to 20 years old.

analyze the role of growth-plate-related genes including COL2A1, COL11A1, ACAN, and FLNB [21, 22]. GnRH agonists may be indicated in children born SGA who are in puberty with predicted adult height 2.5 standard deviations below the mean for their corresponding age and sex [23]. Some children born SGA who are short at the start of puberty may benefit from the combined use of GH and GnRH agonist treatment [23-25].

NS is a genetic condition associated with short stature and is inherited in either an autosomal dominant or de novo (sporadic variant) manner [26]. The incidence of NS is approximately 1 in 1,000-2,500 births. Besides short stature, it is also commonly associated with cardiac abnormalities, characteristic facies, lymphatic dysplasias, and coagulation defects [26-28]. Studies have shown that, in children with NS, prepubertal GH treatment has resulted in increased growth at a rate equivalent to girls with Turner syndrome, although not to the level of children with idiopathic GH deficiency $[27,28]$. The thought is there is a possibly impairment of the GH IGF1 axis. Therefore, GH treatment is an FDA-approved indication for children diagnosed with NS, with nearly $60 \%$ of children with NS obtaining an adult height within one standard deviation of their midparental target height [29]. Without GH treatment, nearly $70 \%$ of children with NS will have short stature throughout adulthood [29, 30]. Side effects from GH treatment in children with NS are infrequently reported. Most notable in regard to NS, GH treatment does not influence cardiac morphogenesis $[29,31]$. One potential mechanism for the GH resistance in NS relates to the PTPN11 variant. PTPN11 encodes SHP2, a protein tyrosine phosphatase involved in GH signaling [20,32]. Therefore, postreceptor GH signaling mutations in SHP2 might explain the mild resistance to GH treatment sometimes seen in NS patients [32]. Additionally, the downstream signaling mutation in SHP2 might also explain the compensatory elevated GH secretion occasionally seen in NS patients [32]. Finally, although recombinant IGF-1 therapy may be a potential treatment in children with NS, to the best of our knowledge, there have been no reports showing the efficacy of IGF-1 in children with NS [33].

Our patient born SGA was also diagnosed with PTPN11related NS after extensive genetic testing. Additionally, genetic testing was not diagnostic for other conditions that could explain her short stature, including GH receptor, IGF1 gene, or GH signaling pathway abnormalities. While children born SGA and children with NS can have significant increases in growth with GH treatment [34], our patient had poor response to GH treatment. Therefore, we hypothesize that the concomitant diagnosis of SGA and PTPN11-related NS may have affected the responsiveness of our patient to the growth-promoting effect of GH therapy. Additionally, it is important to note that genetic workup also elucidated a nondiagnostic VUS in the FGFR3 gene (c.746C > A (p.Ser249Tyr)). While pathogenic variants in this gene can be associated with several genetic syndromes including thanatophoric dysplasia, achondroplasia, Crouzon syndrome, and hypochondroplasia, our patient's phenotype did not fit these diagnoses, and at this time, the significance of this molecular finding is still unclear. 


\section{Conclusions}

We present a case of a 12 11/12-year-old girl born SGA who received GH for 5 years without catch-up growth and was later diagnosed with NS. In turn, the concomitant diagnosis of SGA and NS may have altered the child's ability to respond to $\mathrm{GH}$ treatment.

\section{Data Availability}

No data were used to support this study.

\section{Conflicts of Interest}

The authors declare no conflicts of interest.

\section{References}

[1] G. T. Mandy, L. E. Weisman, and M. S. Kim, "Infants with fetal (intrauterine) growth restriction," 2021, https://www. uptodate.com.

[2] W. K. Cho, B.-K. Suh, and B.-K. Suh, "Catch-up growth and catch-up fat in children born small for gestational age," Korean Journal of Pediatrics, vol. 59, no. 1, pp. 1-7, 2016.

[3] J. Argente, O. Mehls, and V. Barrios, "Growth and body composition in very young SGA children," Pediatric $\mathrm{Ne}$ phrology, vol. 25, no. 4, pp. 679-685, 2010.

[4] A. D. Rogol, "Growth hormone treatment for children born small for gestational age," 2021, https://www.uptodate.com/ contents/growth-hormone-treatment-for-children-born-smallfor-gestational-age.

[5] A. Deodati and S. Cianfarani, "The rationale for growth hormone therapy in children with short stature," Journal of Clinical Research in Pediatric Endocrinology, vol. 9, no. S2, pp. 23-32, 2017.

[6] G. Johannsson, M. Bidlingmaier, B. M. K. Biller et al., "Growth hormone research society perspective on biomarkers of GH action in children and adults," Endocrine Connections, vol. 7, no. 3, pp. R126-R134, 2018.

[7] N. Møller and J. O. L. Jørgensen, "Effects of growth hormone on glucose, lipid, and protein metabolism in human subjects," Endocrine Reviews, vol. 30, no. 2, pp. 152-177, 2009.

[8] G. H. Seo and H.-W. Yoo, "Growth hormone therapy in patients with noonan syndrome," Annals of Pediatric Endocrinology \& Metabolism, vol. 23, no. 4, pp. 176-181, 2018.

[9] C. C. J. Smeets, S. R. Judith, M. v. d. Steen, and A. C. S. Hokken-Koelega, "Metabolic health and long-term safety of growth hormone treatment in silver-russell syndrome," The Journal of Clinical Endocrinology \& Metabolism, vol. 102, no. 3, pp. 983-991, 2017.

[10] P. E. Clayton, S. Cianfarani, P. Czernichow, G. Johannsson, R. Rapaport, and A. Rogol, "Management of the child born small for gestational age through to adulthood: a consensus statement of the international societies of pediatric endocrinology and the growth hormone research society," The Journal of Clinical Endocrinology \& Metabolism, vol. 92, no. 3, pp. 804-810, 2007.

[11] J. Karlberg and K. Albertsson-Wikland, "Growth in full- term small-for-gestational-age infants: from birth to final height," Pediatric Research, vol. 38, no. 5, pp. 733-739, 1995.

[12] A. C. Hokken-Koelega, M. A. D. Ridder, R. J. Lemmen, H. D. Hartog, S. M. D. M. Keizer-Schrama, and S. L. Drop,
"Children born small for gestational age: do they catch up?" Pediatric Research, vol. 38, no. 2, pp. 267-271, 1995.

[13] P. A. Lee, S. D. Chernausek, A. C. S. Hokken-Koelega, and C. Paul, "International small for gestational age advisory board consensus development conference statement: management of short children born small for gestational age," Pediatrics, vol. 111, no. 6, pp. 1253-1261, 2003.

[14] J. Dahlgren and K. A. Wikland, "Final height in short children born small for gestational age treated with growth hormone," Pediatric Research, vol. 57, no. 2, pp. 216-222, 2005.

[15] D. E. Sandberg and L. D. Voss, "The psychosocial consequences of short stature: a review of the evidence," Best Practice \& Research Clinical Endocrinology \& Metabolism, vol. 16, no. 3, pp. 449-463, 2002.

[16] C. J. Kelnar, "Which children should receive growth hormone treatment. cost-benefit analysis is the key," Archives of Disease in Childhood, vol. 83, no. 2, pp. 176-178, 2000.

[17] J. M. Lee, M. M. Davis, S. J. Clark, T. P. Hofer, and A. R. Kemper, "Estimated cost-effectiveness of growth hormone therapy for idiopathic short stature," Archives of Pediatrics \& Adolescent Medicine, vol. 160, no. 3, pp. 263-269, 2006.

[18] A. Grimberg, S. A. DiVall, C. Polychronakos et al., "Guidelines for growth hormone and insulin-like growth factor-I treatment in children and adolescents: growth hormone deficiency, idiopathic short stature, and primary insulin-like growth factor-I deficiency," Hormone Research in Paediatrics, vol. 86, no. 6, pp. 361-397, 2016.

[19] R. G. Rosenfeld, "IGF-I therapy in growth disorders," European Journal of Endocrinology, vol. 157, no. s1, pp. S57-S60, 2007.

[20] S. Loche, L. Carta, A. Ibba, and C. Guzzetti, "Growth hormone treatment in non-growth hormone-deficient children," $A n$ nals of Pediatric Endocrinology \& Metabolism, vol. 19, no. 1, pp. 1-7, 2014.

[21] L. Plachy, V. Strakova, L. Elblova et al., "High prevalence of growth plate gene variants in children with familial short stature treated with GH," The Journal of Clinical Endocrinology \& Metabolism, vol. 104, no. 10, pp. 4273-4281, 2019.

[22] J. B. Quintos, M. H. Guo, and A. Dauber, "Idiopathic short stature due to novel heterozygous mutation of the aggrecan gene," Journal of Pediatric Endocrinology \& Metabolism: JPEM, vol. 28, no. 7-8, pp. 927-932, 2015.

[23] M. J. J. Finken, M. van der Steen, C. C. J. Smeets et al., "Children born small for gestational age: differential diagnosis, molecular genetic evaluation, and implications," Endocrine Reviews, vol. 39, no. 6, pp. 851-894, 2018.

[24] M. van der Steen, A. J. Lem, D. C. M. v. d. van der Kaay, and A. C. S. Hokken-Koèelega, "Puberty and pubertal growth in GH-treated SGA children: effects of 2 years of GnRHa versus no GnRHa," The Journal of Clinical Endocrinology \& Metabolism, vol. 101, no. 5, pp. 2005-2012, 2016.

[25] A. J. Lem and D. C. M. v. d. van der Kaay, M. A. J. d. Ridder et al., "Adult height in short children born SGA treated with growth hormone and gonadotropin releasing hormone analog: results of a randomized, dose-response GH trial," The Journal of Clinical Endocrinology \& Metabolism, vol. 97, no. 11, pp. 4096-4105, 2012.

[26] A. A. Romano, J. E. Allanson, J. Dahlgren et al., "Noonan syndrome: clinical features, diagnosis, and management guidelines," Pediatrics, vol. 126, no. 4, pp. 746-759, 2010.

[27] P. A. Lee, J. L. Ross, B.T. Pedersen, P. Kotnik, J. A. Germak, and H. T. Christesen, "Noonan syndrome and turner syndrome patients respond similarly to 4 years' growth-hormone 
therapy: longitudinal analysis of growth-hormone-naïve patients enrolled in the $\mathrm{NordiNet}^{\circledR}$ international outcome study and the ANSWER program," International Journal of Pediatric Endocrinology, vol. 2015, no. 1, pp. 1-9, 2015.

[28] N. Zavras, C. Meazza, A. Pilotta et al., "Five-year response to growth hormone in children with noonan syndrome and growth hormone deficiency," Italian Journal of Pediatrics, vol. 41, no. 1, pp. 71-76, 2015.

[29] J. A. Noonan, A.-M. Kappelgaard, and A.-M. Kappelgaard, "The efficacy and safety of growth hormone therapy in children with noonan syndrome: a review of the evidence," Hormone Research in Paediatrics, vol. 83, no. 3, pp. 157-166, 2015.

[30] J. A. Noonan, R. Raaijmakers, and B. Hall, "Adult height in noonan syndrome," American Journal of Medical Genetics Part A, vol. 123, no. no. 1, pp. 68-71, 2003.

[31] A. M. Cotterill, W. J. McKenna, A. F. Brady et al., "The shortterm effects of growth hormone therapy on height velocity and cardiac ventricular wall thickness in children with noonan's syndrome," The Journal of Clinical Endocrinology \& Metabolism, vol. 81, no. 6, pp. 2291-2297, 1996.

[32] G. Binder, K. Neuer, M. B. Ranke, and N. E. Wittekindt, "PTPN11 mutations are associated with mild growth hormone resistance in individuals with noonan syndrome," The Journal of Clinical Endocrinology \& Metabolism, vol. 90, no. 9, pp. 5377-5381, 2005.

[33] P. F. Collett-Solberg and M. Misra, "The role of recombinant human insulin-like growth factor-I in treating children with short stature," The Journal of Clinical Endocrinology \& Metabolism, vol. 93, no. 1, pp. 10-18, 2008.

[34] A.-M. Kappelgaard and T. Laursen, "The benefits of growth hormone therapy in patients with turner syndrome, noonan syndrome and children born small for gestational age," Growth Hormone \& IGF Research, vol. 21, no. 6, pp. 305-313, 2011. 